\title{
VANTAGEM COMPARATIVA E MATRIZ DE COMPETITIVIDADE DO MATE BRASILEIRO E ARGENTINO, NO PERÍODO DE 1997-2011
}

\author{
COMPARATIVE ADVANTAGE AND MATRIX OF COMPETITIVENESS OF BRAZILIAN AND \\ ARGENTINA MATE, THE PERIOD 1997-2011
}

Elisangela Lobo Schirigatti ${ }^{1}$ João Carlos Garzel Leodoro da Silva ${ }^{2}$ Alexandre Nascimento de Almeida ${ }^{3}$ Anadalvo Juazeiro dos Santos ${ }^{4}$ Neusa de Almeida Rucker ${ }^{5}$

\section{RESUMO}

Esse artigo teve por objetivo analisar o desempenho das exportações do Brasil e da Argentina no mercado internacional de mate. O método de análise utilizado refere-se ao Índice de Vantagem Comparativa Revelada (IVCR) do mate brasileiro e argentino, durante o período de 1997 a 2011. Inicialmente, foi verificada a existência de quebras estruturais das séries temporais e depois, foram averiguados a taxa de crescimento de mercado e o Índice de Vantagem Comparativa Revelada Simétrica (IVCRS) que foram utilizados para identificar a posição do mate de cada país na matriz de competitividade. Os resultados obtidos no período integral mostraram que tanto o mate brasileiro quanto o argentino apresentaram produtos que possuem vantagem comparativa $(+)$ dentro de mercados com demanda crescente $(+)$.

Palavras-chave: exportações; competitividade; mercado internacional.

\begin{abstract}
This article aims to analyze the performance of exports from Brazil and Argentina in the international mate market. The analysis method used refers to the Revealed Comparative Advantage Index (IVCR) of the Brazilian and Argentine mate, during the period from 1997-2011. At the beginning, it was verified the existence of structural breaks of the time series, then, were investigated the rate of market growth and the Symmetric Revealed Comparative Advantage Index (IVCRS) that were used to identify the mate position of each country in the competitiveness matrix. The results obtained in the whole period showed that both the Brazilian and Argentine mate presented products that have comparative advantage $(+)$ in markets with increasing demand $(+)$.
\end{abstract}

Keywords: exports; competitiveness; international market.

\section{INTRODUÇÃO}

A erva-mate (Ilex paraguariensis Aug. St. -Hil) historicamente tem apresentado importância socioeconômica para o desenvolvimento da região sul do Brasil, bem como para a Argentina, onde seu uso tradicional sempre foi, através do beneficiamento de seus talos e folhas, o chimarrão, o tereré e o chá (MAZUCHOWSKI, 2004), porém, atualmente, outros produtos à base de erva-mate têm sido realizados, tanto na química fina (MAZUCHOWSKI; RUCKER, 1997; INPI, 2013) como na área de beleza (DE

1 Designer de Produto, Dr ${ }^{\mathrm{a}}$., Professora do Departamento de Desenho Industrial, Universidade Tecnológica Federal do Paraná, Av. Sete de Setembro, 3165, CEP 80230-901, Curitiba (PR), Brasil. elisangelal@utfpr.edu.br

2 Engenheiro Florestal, Dr., Professor da Universidade Federal do Paraná, Rua dos Funcionários, 1540, CEP 80035050, Curitiba (PR), Brasil.garzel@ufpr.br

3 Engenheiro Florestal, Dr., Professor da Faculdade de Planaltina, Universidade de Brasília, Área Universitária n. 1, Vila Nossa Senhora de Fátima, CEP 73300-000, Planaltina (DF), Brasil. alexalmeida@unb.br

4 Engenheiro Florestal, Dr., Professor da Universidade Federal do Paraná, Rua dos Funcionários, 1540, CEP 80035050, Curitiba (PR), Brasil. ajsantos@ufpr.br

5 Cientista Social, $\mathrm{Dr}^{\mathrm{a}}$., Pesquisadora Cientifica da Cadeia Produtiva do Mate, Rua Alferes Ângelo Sampaio, 2782, CEP 80730-460, Curitiba (PR), Brasil. neusamate@gmail.com

Recebido para publicação em 3/11/2013 e aceito em 7/08/2017

Ci. Fl., v. 28, n. 4, out. - dez., 2018 
PAULA; CHOCIAI, 2000), mostrando que, inversamente à percepção que inicialmente possa se ter de queda de sua utilização, o potencial de crescimento é evidente e promissor.

Contudo, para se analisar esta espécie no comércio internacional, é preciso se reportar ao Sistema Harmonizado de designação e codificação de mercadorias (SH), sendo que os produtos advindos da ervamate são identificados por "mate" com Código 0903 (WORLD CUSTOMS ORGANIZATION, 2013) e classificados segundo a Nomenclatura Comum do Mercosul (NCM), que é baseada no SH, em três tipos: 1) mate simplesmente cancheado (0903.00.90); 2) outros tipos de mate (0903.00.10); e 3) extratos, essências, concentrados e preparados de mate (2101.20.20) (BRASIL, 2012).

Estatísticas recentes mostram que o Brasil e a Argentina são os maiores produtores e exportadores mundiais de mate(ORGANIZAÇÃO DAS NAÇÕES UNIDAS PARAALIMENTAÇÃOEAGRICULTURA, 2012), mas a relação no comércio exterior do produto brasileiro é histórica e remonta à época colonial (SAINT-HILAIRE, 1964; LINHARES, 1969). E foi no final da década de 1920, que o ciclo da erva-mate no Brasil atingiu seu auge ao exportar 92,6 mil toneladas somente em 1926 (IBGE, 2011) uma quantidade 2,6 vezes maior que o observado em 1997 (BRASIL, 2012), sendo que essa redução derivou de diversos fatores, entre eles, desencadeado pela Argentina que, de maior consumidora da erva-mate brasileira, passou a ser uma grande exportadora do produto (LINHARES, 1969; OLIVEIRA, 1974).

Há, entretanto, outras diferenças entre o Brasil e a Argentina. Enquanto no Brasil há uma divisão equitativa entre ervais nativos e plantados, sendo que os primeiros reduziram a partir da década de 70 , principalmente para a transformação do solo para lavouras temporárias (COSTA, 1989; VEGRO, 1994), na Argentina predominam os ervais plantados que são cultivados de forma intensiva, que surgiram devido aos investimentos em pesquisa e extensão rural, em especial com a aplicação de tecnologias para simplificar e mecanizar o processo produtivo (DANIEL, 2009; MEDRADO; VILCAHUAMAN, 2010).

Verifica-se que o mercado internacional de mate, apesar das oscilações a partir da década de 1990, tem apresentado uma tendência de crescimento, aquecimento esse que tem contado com a presença dos dois países, Brasil e Argentina. Contudo, com relação à quantidade produzida, as exportações brasileiras de mate são percentualmente pequenas, enquanto para a produção Argentina o percentual exportado é comparativamente bem maior (DANIEL, 2009).

Mais do que já debatido em vários artigos, é fundamental tanto em nível nacional, como para os próprios setores, que as exportações geram divisas e incentivam o aperfeiçoamento da cadeia de valor. E isso não é diferente para o segmento da erva-mate frente aos quesitos de qualidade, pesquisa e desenvolvimento (MAZUCHOWSKI; RUCKER, 1997).

Considerando a divisão do mercado mundial de mate entre Brasil e a Argentina (os outros países, portanto, são marginais neste mercado), é de fundamental importância avaliar a intensidade e evolução da competitividade dos dois principais países no mercado internacional do mate.

Dentro deste objetivo, avaliação da competitividade, o estudo estabeleceu os seguintes objetivos secundários de apoio ao principal: a) analisar o Índice de Vantagem Comparativa Revelada (IVCR) do mate brasileiro e argentino, no período de 1997 a 2011 e; b) identificação da posição desses produtos na matriz de competitividade.

\section{MATERIAIS E MÉTODOS}

\section{Referencial teórico}

Com base no pressuposto fundamentado na teoria econômica clássica Ricardiana (RICARDO, 1821), de que cada país deveria se especializar na commodity de menor desvantagem absoluta, Balassa (1965) formulou o Índice de Vantagem Comparativa Revelada (IVCR), que possibilita analisar a competitividade a partir das informações passadas dos fluxos comerciais.

Esta medida, também conhecida como Índice de Balassa ou Índice da Vantagem de Exportação Revelada, é amplamente consagrada na literatura econômica e aplicada por muitos autores de diversas áreas (COXHEAD, 2007; SERIN; CIVAN, 2008; JACKMAN et al., 2011; WEI; FANG; FENG, 2011; BAKHSHINEJAD; ZADEH, 2012; GUO; WANG; NIE, 2012; SILVA, 2012; BRAKMAN et al., 2013; KARAALP; YILMAZ, 2013). 
Dentre as pesquisas que envolveram produtos de base florestal destacam-se Dieter e Englert (2007), que avaliaram a competitividade global da indústria florestal; Han, Wen e Kant (2009) que estudaram a indústria de móveis de madeira; Zhu e Zhang (2010) que estudaram a competitividade chinesa para produtos de papel; Almeida, Silva e Angelo (2012) que avaliaram a performance das exportações de madeira macia do Brasil e Canadá; Petrauski (2012) que abordou a competitividade do Brasil no mercado internacional de madeira serrada; Mahanzule (2013) que analisou a competitividade das exportações moçambicanas de produtos de madeira;

O IVCR é um indicador do comércio exterior que permite identificar produtos com melhores condições de inserção internacional (FERNANDES; VIEIRA FILHO, 2000). De acordo com Ilha e Souza (2005), o IVCR ressalta a importância de determinado produto na pauta de exportação nacional em relação às exportações mundiais. Carvalho et al. (2010) comentam que essa importância está relacionada com a parcela de contribuição das exportações do produto analisado na pauta de exportação total de um país, mesmo que esse país apresente exportações totais menores em comparação com as exportações totais realizadas por outro país no mesmo período.

Couto e Ferreira (2010) explicam que, quando o índice supera a unidade é sinal que o país possui uma posição mais vantajosa nacionalmente na produção e na exportação do produto analisado do que sua participação relativa nas exportações totais do país. Com base nessa lógica, quanto maior o volume exportado de um produto por um país, maior será sua vantagem comparativa na produção desse bem e, consequentemente, maior o IVCR (CONFEDERAÇÃO NACIONAL DA INDÚSTRIA, 2008).

Para Couto e Ferreira (2010), os valores crescentes do IVCR de um país para determinado produto indicam que as exportações do país com relação a esse produto estão ganhando espaço no mercado internacional. Ilha e Coronel (2006) associam o aumento do IVCR com a alta da produção e com episódios de desvalorização da moeda. Por outro lado, os mesmos autores relacionam a queda do índice com fatores como: sobrevalorização cambial da moeda nacional, aumento das exportações mundiais do produto analisado e queda das exportações do mesmo produto nos países analisados.

O cálculo da IVCR tem base em dados observados, por isso definido como "revelada", e demonstra as vantagens comparativas de um país na produção de determinado bem ou setor de atividade, procurando avaliar a competitividade a partir de seus efeitos e resultados (HIDALGO, 1998).

Apesar de muito aplicado, Pais, Gomes e Coronel (2012) comentam que o sucesso da indústria não pode ser atribuído somente à vantagem comparativa, e alerta para as limitações do indicador IVCR. Uma delas é por estar pautado no conceito de desempenho e não explicitar os fatores que explicam a competitividade, além de ser influenciado por variáveis relacionadas ao desempenho do setor externo, mas não necessariamente à competitividade, como por exemplo, a contração do mercado interno.

Por isso Li, Dunford e Yeung (2012), comentam que, quando os resultados dos valores relativos de competitividade apresentam melhorias, significa que o indicador pode sofrer influência positiva de diversos fatores, tais como: evolução dos fatores de produção, qualidade na infraestrutura logística e de comunicações, conjunto de políticas governamentais, conjunto de mecanismo de política industrial projetado para promover aumentos de conteúdo local e de transferência de tecnologia, fortalecendo as dotações de recursos. Quando o mesmo decresce reflete a necessidade progressiva do país em questão de determinado recurso.

O IVCR é utilizado como base para a confecção da matriz de competitividade, uma metodologia proposta por Fajnzyberg (1991) e Mandeng (1991), ainda aplicada por muitos autores (XAVIER, 2001; PENA, 2004; OLIVEIRA, 2005; MOREIRA; HERREROS, 2010; MAHANZULE, 2013).

De acordo com Pena (2004), a matriz foi desenvolvida para representar o dinamismo das exportações de um país em um determinado ponto no tempo, característica que é evidenciada quando se relaciona a dinâmica da estrutura exportadora desse país com a do comércio internacional.

O mesmo autor relata que dentro da lógica da matriz de competitividade, o país melhora sua inserção no mercado internacional à medida que concentra suas exportações em setores com elevada demanda externa e, consequentemente, a perpetuação da competitividade dependerá dos ajustes de manutenção ou aumento dos ganhos de mercados.

A partir disso, as exportações do país analisado podem ser classificadas em quatro setores: 1) Ótimos; 2) Em declínio; 3) Oportunidades perdidas; e 4) Em retrocesso. O primeiro setor inclui os países 
que ganham participação em um mercado de um produto que apresenta demanda crescente. A segunda situação envolve ganho de mercado com produtos de demanda decrescente. $O$ terceiro caso associa perda de mercado com produtos de demanda crescente. Por fim, os setores em retrocesso identificam países que perdem participação em mercados de produtos com demanda internacional decrescente (NAÇÕES UNIDAS, 2002).

\section{Referencial Analítico}

\section{Estabilidade estrutural das séries temporais}

De acordo com Gujarati (2006), as observações dispostas em um longo período de tempo podem apresentar uma quebra estrutural, indicando que os parâmetros do modelo da série temporal mudaram em determinado momento do período considerado. Essa constatação é importante pois, caso esta quebra seja identificada, o modelo de tendência calculado pode deixar de representar a média do comportamento da variável em questão, resultando em análises estatísticas distorcidas.

Diferentemente de alguns autores (ALMEIDA; SILVA; ANGELO, 2012) que determinaram os períodos para aplicação do IVCR conforme eventos macroeconômicos importantes, definiu-se os períodos de análise por meio da estatística, utilizando o teste de Chow. Inicialmente, foi realizada uma análise visual dos gráficos das séries temporais e foram identificadas as possíveis quebras estruturais. Assim, para cada possível subperíodo foi proposto um modelo equacional e um outro para o período total de cada série analisada.

O teste de Chow foi aplicado para identificar e confirmar a existência de possíveis quebras estruturais nas séries temporais inferidas visualmente, utilizando-se o software Gretl 1.9.9, de acordo com a metodologia apresentada por Gujarati (2006). Com isso, por meio do método dos Mínimos Quadrados Ordinários (MQO) estimou-se a soma dos quadrados do resíduo da taxa de crescimento do período completo (SQR1) de cada série temporal e a soma dos quadrados do resíduo das taxas de crescimento dos períodos a serem avaliados (SQR2 e SQR3) assim como seus respectivos graus de liberdade (n1-k, n2-k, n1 + n2 - 2k), aplicando os resultados na seguinte fórmula (1):

$$
F=\frac{S Q R_{5} / k}{S Q R_{4} /\left(n_{1}+n_{2}-2 k\right)}
$$

Em que: $\mathrm{SQR} 4=(\mathrm{SQR} 2+\mathrm{SQR} 3)$ e $\mathrm{SQR} 5=(\mathrm{SQR} 1-\mathrm{SQR} 4)$

No caso do valor $F$ estimado exceder o valor crítico tabelado de $\mathrm{F}$ ao grau de probabilidade ( $\alpha$ ) escolhido, rejeita-se a Hipótese Nula $\left(\mathrm{H}_{0}\right)$ ausência de mudança estrutural, considerando que:

$$
\begin{aligned}
& \mathrm{H}_{0} \text { : Os parâmetros das regressões são estáveis. } \\
& \mathrm{H}_{1} \text { : Não há estabilidade dos parâmetros das regressões. }
\end{aligned}
$$

Segundo Gujarati (2006), o teste de Chow pressupõe que: 1. Os termos de erros nas regressões dos subperíodos são homocedásticos, ou seja, que se distribuem com a mesma variância: u1t $\sim \mathrm{N}(0, \sigma 2)$ e $\mathrm{u} 1 \mathrm{t} \sim \mathrm{N}(0, \sigma 2)$ e 2 . Os dois termos de erro, u1t e u1t têm distribuições independentes. Por isso, na sequência foram realizados os testes de White e de Durbin-Watson para a verificação de heterocedasticidade e da correlação serial entre os resíduos, respectivamente.

\section{Posição no mercado de mate - Market share}

Nesse estudo, o market share é aplicado para identificar a participação percentual do Brasil e da Argentina no mercado mundial de mate. Segundo Dias, Gibbertt e Shikida (2008), o indicador é obtido por meio do valor das exportações de mate realizadas pelo país em relação ao valor das exportações mundiais 
de mate, sendo esse resultado multiplicado por 100 . Como os valores variam entre 0 e 100 , quanto mais alto o valor maior a intensidade de participação do país no mercado internacional do produto selecionado.

\section{Índice de Vantagem comparativa revelada (IVCR)}

Nesse estudo, o IVCR fornece um indicador da participação relativa das exportações do Brasil e da Argentina e demonstra se esses países possuem vantagem comparativa com o mate, comparando sua participação nos mercados nacional e internacional, a fim de caracterizar a trajetória de exportação desses países. De acordo com a base estrutural descrita em Balassa $(1965,1977)$, o IVCR pode ser mensurado conforme a fórmula (1):

$$
\operatorname{IVCR}=\left(X_{i j} / X_{i}\right) /\left(X_{w j} / X_{w}\right)(1)
$$

Em que: $\mathrm{IVCR}_{\mathrm{j}}=$ indicador de vantagem comparativa revelada do produto $j ; \mathrm{X}_{\mathrm{ij}}=$ valor das exportações do país $i$ do produto $j ; \mathrm{X}_{\mathrm{i}}=$ valor total das exportações do país $i ; \mathrm{X}_{\mathrm{wj}}=$ valor das exportações mundiais $w$ do produto $j$; $\mathrm{X}_{\mathrm{w}}=$ valor das exportações mundiais $w$.

A interpretação dos resultados considera que: se o índice de vantagem comparativa for superior à unidade (IVCR $>1$ ), implica dizer que o Brasil ou a Argentina apresentaram vantagem comparativa no mercado de mate, expressando um market share superior desse produto no mercado mundial (YUE; HUA, 2002).

No entanto, se IVCR $<1$ é sinal de desvantagem comparativa (LAURSEN, 1998) e nesse caso indica que a participação do mate do Brasil ou da Argentina é menor do que a parcela correspondente no mundo. Porém, quando o resultado for igual à unidade $(\mathrm{IVCR}=1)$ é sinal que o mate se apresenta dentro da média do mercado mundial. Assim, quanto mais alto o IVCR, maior será a vantagem comparativa desses países para o mate em comparação aos outros produtos da pauta de exportação.

De acordo com Balassa $(1965 ; 1977)$, se o índice for maior que 2,5 significa que o país possui uma vantagem comparativa extremamente forte desse produto no mercado internacional em relação aos outros produtos da sua pauta de exportação. Se o índice variar ente 2,5 e 1,25 indica que o país apresenta uma vantagem comparativa forte, se ficar entre 0,8 e 1,25 mostra que o país tem uma vantagem comparativa moderada e se estiver abaixo de 0,8 aponta a existência de uma desvantagem comparativa fraca.

\section{Matriz de competitividade}

A evolução dos fluxos de exportação de um país e o comportamento da demanda internacional são as variáveis empregadas na construção da matriz de competitividade. São utilizados os dados do Índice de Vantagem Comparativa Revelada Simétrica (IVCRS) no eixo vertical e a taxa de crescimento do mercado, calculada por meio do método dos Mínimos Quadrados Ordinários (MQO) que é disponibilizada no eixo horizontal.

Conforme ressalta Laursen (1998), os resultados do IVCR possuem uma restrição estatística, pois os valores obtidos são assimétricos, ou seja, podem variar entre 0 e $\infty$. Para padronizar os resultados e facilitar a aplicação dos mesmos na matriz de competitividade, a solução utilizada pelos autores foi obter valores IVCR dentro de um intervalo de referência por meio da seguinte fórmula (2). 


$$
I V C R S_{j}=\left(I V C R_{j}-1\right) /\left(I V C R_{i j}+1\right)(2)
$$

Em que: $\operatorname{IVCRS}_{\mathrm{ij}}=$ vantagem comparativa revelada simétrica do produto $j$ do país $i$.

Desta maneira, o índice IVCR torna-se simétrico (IVCRS), pois os valores situam-se entre -1 e +1 com um ponto médio centrado no zero, sendo que esta variável é aplicada no eixo $y$.

Compondo o eixo horizontal, está a taxa de crescimento que foi obtida nesse estudo empregando-se a metodologia que teve origem no cálculo dos juros compostos e foi descrita por Gujarati (2006), aplicada por Brasil (2002) e Almeida et al. (2009a; 2009b), sendo obtida por meio da aplicação do método dos Mínimos Quadrados Ordinários (MQO).

Para o processo de cálculo da taxa de crescimento utilizou-se a seguinte lógica: $\mathrm{Y}_{\mathrm{t}}=\mathrm{V}_{\mathrm{t}}$ (valor de exportação do mate no instante t) de acordo com a equação (3):

$$
\mathrm{Y}_{t}=\mathrm{Y}_{0}(1+r)^{t}
$$

Em que: $\mathrm{Y}_{\mathrm{t}}=$ valor considerando a taxa ao longo do tempo $\mathrm{t} ; \mathrm{Y}_{0}=$ valor inicial; $r=$ taxa composta ou geométrica, isto é, ao longo do tempo, de $\mathrm{Y} ; \mathrm{t}$ = período. A equação (1) foi reescrita ao se calcular o logaritmo natural conforme (4):

$$
\ln Y_{t}=\ln Y_{0}+t \ln (1+r)
$$

Sendo que: $\beta_{0}=\ln Y_{0}$ e $\beta_{1}=\ln (1+\mathrm{r})$, pode-se escrever e adicionar o termo de perturbação $\mu_{t}$ na equação (5), para se obter o seguinte modelo:

$$
\ln V t=\beta_{0}+\beta_{1} t+\mu_{t}
$$

Em que: $V_{t}=$ valor exportado de mate no ano $t ; t=$ variável tendência $(X=t)$, medida em ano; $\mu_{t}=$ termo de perturbação;

O método ajusta a tendência linear de uma variável em equações de modelo semilogarítmico ou semilog, no qual o coeficiente de inclinação angular $\beta_{1}$ mede a variação relativa constante em Y para uma dada variação absoluta no valor do regressor $t$, conforme a fórmula (6):

$$
\beta_{1}=\frac{V R Y}{V A X}
$$

Em que: VRY = variação relativa no regressando $(Y)$ e VAX = variação absoluta no regressor $(X)$.

Depois de realizadas as regressões, multiplicou-se a variação relativa de Y por $100\left(\beta_{1} x 100\right)$ para se obter a variação percentual que é a taxa de crescimento instantânea, isto é, em um ponto no tempo. Para fins de comparação em geral, a variação relativa apresenta maior relevância o que justifica a escolha do modelo de taxa de crescimento nesse estudo ao invés do modelo de tendência linear, no qual se utiliza uma regressão de $\mathrm{Y}$ contra o tempo e não a regressão do $\log$ de $\mathrm{Y}$, como ocorreu nesse caso.

Na sequência, a taxa de crescimento instantânea foi utilizada para o cálculo da taxa de crescimento composta, ou seja, ao longo do período, que foi obtida por meio da seguinte equação (7):

$$
r=\left[\left(\operatorname{anti} \log \beta_{1}-1\right) * 100\right]
$$

Segundo Gujarati (2006), a taxa composta, em geral, apresenta-se mais alta que a taxa de crescimento instantânea, fato que se deve ao efeito da composição.

Desta maneira, a estrutura da matriz de competitividade é formada por quatro quadrantes e dependendo da posição do enquadramento obtido nos resultados pode-se identificar a situação competitiva do país (NAÇÕES UNIDAS, 2002) e distinguir quatro situações estratégicas distintas: 1) Situação Ótima: 
posicionamento favorável e eficiência alta; 2) Situação de oportunidades perdidas: posicionamento favorável e eficiência baixa; 3) Situação de vulnerabilidade: posicionamento desfavorável e eficiência alta; e 4) Situação de retirada: posicionamento desfavorável e eficiência baixa (NAÇÕES UNIDAS, 2002).

Com base nessa lógica, alguns autores realizaram suas análises considerando os setores dinâmicos aqueles que apresentam taxa de crescimento positiva $(+)$ no mercado mundial e os setores não dinâmicos, aqueles que exibem uma taxa de crescimento negativa (-) (PENA, 2004; MOREIRA; HERREROS, 2010). Assim, como os setores competitivos são aqueles que apresentam o IVCRS positivo $(+)$ e os setores não competitivos aqueles que possuem o IVCRS negativo (-), conforme mostra o design da Figura 1.

Desta forma, o quadrante superior esquerdo indica os setores em declínio ou que se encontram em situação de vulnerabilidade e que correspondem aos produtos que apresentam IVCRS $(+)$ em setores de demanda declinante (-). O quadrante superior direito mostra os setores ótimos que englobam os produtos que possuem vantagem comparativa $(+)$ dentro de mercados com demanda crescente $(+)$.

$\mathrm{O}$ quadrante inferior esquerdo marca os setores em retrocesso ou em situação de retirada e representam produtos sem vantagem comparativa revelada (-) dentro de setores com demanda decrescente (-). Por fim, o quadrante inferior direito define os setores que estão em situação de oportunidades perdidas e enquadram produtos com forte dinâmica da demanda crescente $(+)$ mas que não apresentam vantagens comparativas reveladas negativas (-).

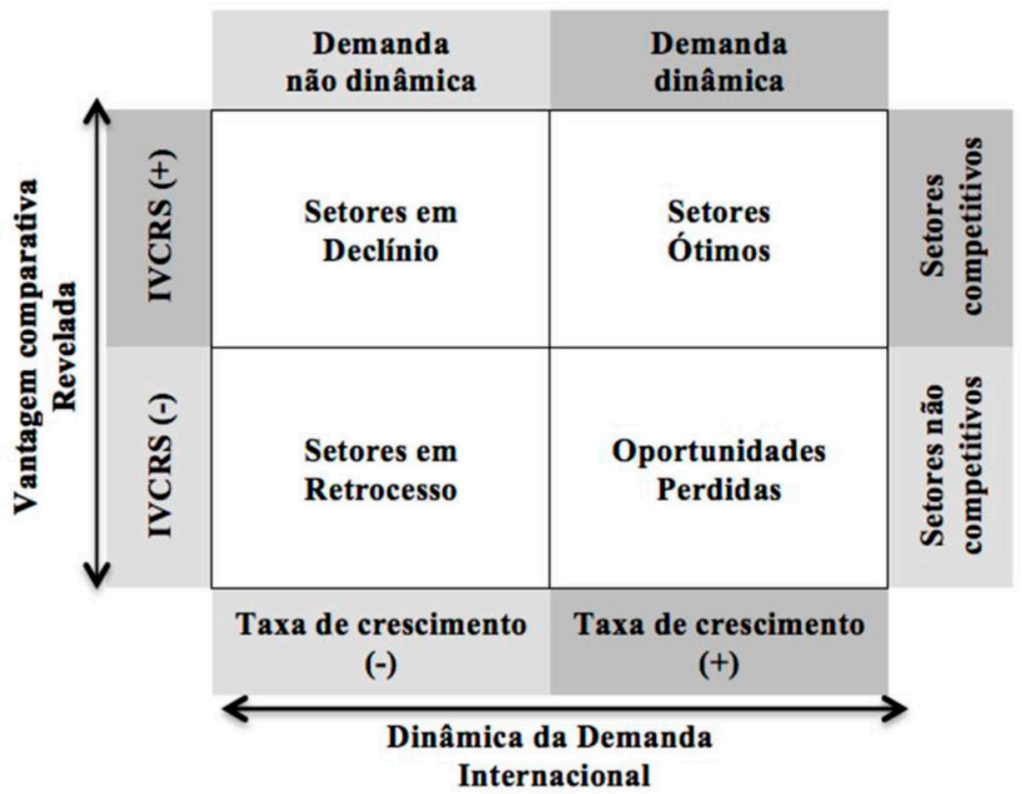

FIGURA 1: Matriz de competitividade [Fonte: Mandeng (1991) e Nações Unidas (2002)].

FIGURE 1: Matrix competitiveness.

\section{Dados utilizados}

No artigo em questão, os dados são secundários (SAMPIERI, 2006) e compõem séries temporais em periodicidade anual. O período definido pelo estudo abrangeu o intervalo de 1997 a 2011 para as exportações brasileiras e argentinas do mate, totalizando uma amostra de 15 anos.

Para a composição das séries históricas foi considerado o código para o mate 0903 da Nomenclatura Comum do Mercosul/Sistema Harmonizado de designação e codificação de mercadorias (NCM/SH) criado pelo World Customs Organization (WORLD CUSTOMS ORGANIZATION, 2013).

É importante ressaltar que a análise considerou o mate no agregado, cujo código inclui as exportações de mate simplesmente cancheado (0903.00.90) e outros tipos de mate (0903.00.10). O primeiro código designa a erva-mate (Ilex paraguariensis Aug. St. Hill) que passa pelo beneficiamento primário de trituração e secagem, servindo de base para a produção dos produtos de mate. O segundo código engloba produtos já beneficiados, tais como: o chimarrão, chá e o tereré. Essa escolha ocorreu devido à ausência de códigos com oito dígitos no banco de dados consultado, que possibilitam a identificação desses produtos de 
forma mais específica.

Os valores em dólar (US\$) Free On Board (FOB) referentes à exportação utilizados nesta pesquisa foram obtidas das Nações Unidas, o United Nations Commodity Trade Statistics Database (UN COMTRADE, 2012), do United States Department of Agriculture (USDA) disponibilizado pelo Serviço de Agricultura Estrangeiro. As séries foram deflacionadas utilizando-se o Índice de Preços ao Consumidor dos EUA (CPI) disponibilizado pelo U. S. Departament of Bureau of Labor Statistics (2012), considerando como base o ano de 2011.

\section{RESULTADOS E DISCUSSÃO}

\section{Estabilidade estrutural das séries temporais}

Entre 1997 e 2011, o Brasil e a Argentina dominaram 92\% das exportações mundiais de mate, sendo que o Brasil respondeu por 49,7\% e a Argentina por 42,3\% (Figura 2), mostrando uma pequena dominância do Brasil. Os outros 8\% corresponderam a 109 países que registraram exportações de mate, entre eles destacam-se a Indonésia com $1,5 \%$, a Alemanha e o Paraguai com $0,8 \%$ cada um, e o Uruguai com $0,6 \%$.

Por consequência, a tendência das exportações de mate mundial foi modelada pelo comportamento das exportações do Brasil e da Argentina como pode ser visto na Figura 2, e mostraram duas trajetórias distintas. A primeira delas foi caracterizada por um movimento de angulação negativa que começou em 1997 e se estendeu até 2003, na sequência, o segundo percurso descreveu um deslocamento positivo que se manteve até o final da série em análise, 2011.

Ao realizar o teste Chow para Brasil, Argentina e mundo verificou-se que para o Brasil a quebra estrutural mais forte aconteceu em $2003(\mathrm{~F}(2,11)=139.171 ; \mathrm{p}<0,01)$, enquanto para a Argentina $(\mathrm{F}(2,11)=$ $137.85 ; \mathrm{p}<0,01)$ e para o Mundo $(\mathrm{F}(2,11)=340.347 ; \mathrm{p}<0,01)$ ocorreu em 2004 .

Porém, todas elas foram significativas em 2003 em nível de $p 1 \%$. Assim, optou-se por dividir a série neste ano, considerando a importância do Brasil como foco principal da análise do estudo. Assim, o estudo analisou o desempenho das exportações brasileiras e argentinas de mate no período de 1997 a 2011 e nos subperíodos de 1997 a 2003 e de 2004 a 2011.
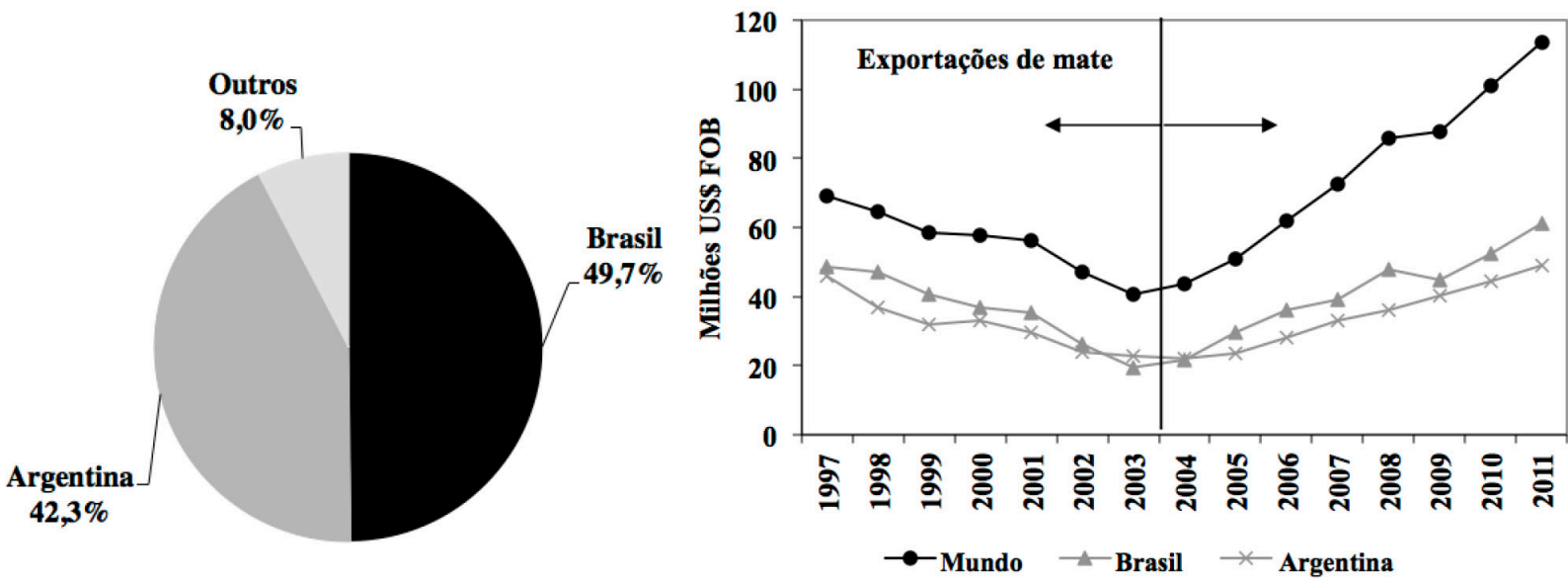

FIGURA 2: Percentual das exportações mundiais de mate por país, no período de 1997 a 2011; e Exportações brasileiras do mate de acordo com o valor de exportação, no período de 1997 a 2011 [Fonte: Brasil (2011) e Un Comtrade (2011)].

FIGURE 2: Percentage of world exports of mate by country, in the period 1997-2011; and Brazilian exports mate according to the value of exports, in the period 1997-2011. 


\section{Índice de Vantagem Comparativa Revelada do mate brasileiro e argentino}

Durante o período analisado (1997-2011), as exportações brasileiras de mate apresentaram um crescimento positivo que alcançou $1,9 \%$ a.a. (ao ano), uma taxa maior que a apresentada pelas exportações mundiais de mate ( $1,6 \%$ a.a.) e que aquela obtida pelas exportações argentinas de mate $(1,3 \%$ a.a.) no mesmo período (Tabela 1).

TABELA 1: Taxa de crescimento das exportações mundiais, brasileiras e argentinas de mate, no período de 19972011 e nos subperíodos 1997-2003 e 2004-2011.

TABLE 1: $\quad$ Rate of growth export of Argentine, Brazilian and world of mate, in the period 1997-2011 and the sub periods 1997-2003 and 2004-2011.

\begin{tabular}{cccc}
\hline País & $\begin{array}{c}1997-2011 \\
\text { (\%a.a.) }\end{array}$ & $\begin{array}{c}1997-2003 \\
\text { (\%a.a.) }\end{array}$ & $\begin{array}{c}2004-2011 \\
\text { (\%a.a.) }\end{array}$ \\
\hline Mundo & $1,56^{\dagger}$ & $9,94^{\dagger}$ & $11,79^{\dagger}$ \\
Brasil & $1,86^{\dagger}$ & $13,44^{\dagger}$ & $13,98^{\dagger}$ \\
Argentina & $1,33^{\dagger}$ & $10,38^{\downarrow}$ & $12,41^{\dagger}$ \\
\hline
\end{tabular}

Fonte: Os autores de acordo com Brasil (2011) e Un Comtrade (2011).

No entanto, ao analisar o primeiro subperíodo, verificou-se que as exportações brasileiras de mate $(-13,4 \%$ a.a.) apresentaram uma queda maior em comparação às taxas apresentadas pelo mundo ( $-9,9 \%$ a.a.) e pela Argentina (-10,4\% a.a.). Em compensação, seu crescimento no segundo subperíodo foi maior que da Argentina (12,4\% a.a.) e da taxa mundial (11,8\% a.a.).

Entre 1997 e 2011, o mercado mundial de mate movimentou um valor superior a US\$ FOB 1,0 bilhão e as exportações brasileiras de mate corresponderam a 49,9\% desse montante, ou seja, US\$ FOB 504,3 milhões, o equivalente a $0,04 \%$ das exportações totais realizadas pelo Brasil (Tabela 2), sendo que, no mesmo período, as exportações argentinas de mate atingiram US\$ FOB 429,2 milhões e representaram $42,5 \%$ do mercado mundial de mate, o que equivaleu a $0,07 \%$ das exportações totais argentinas. 
TABELA 2: Participação das exportações de mate com relação às exportações totais de cada país e às exportações mundiais de mate; IVCR e IVCRS do mate argentino e brasileiro, no período de 1997-2011.

TABLE 2: $\quad$ Share of exports to mate with total exports of each country and the world exports mate, mate IVCR and IVCRS Argentina and Brazil, in the period 1997-2011.

\begin{tabular}{ccccc|cccc}
\hline Ano & \multicolumn{3}{c}{ Brasil } & & & \multicolumn{4}{c}{ Argentina } \\
\cline { 2 - 8 } & $\mathrm{A}(\%)$ & $\mathrm{B}(\%)$ & IVCR & IVCRS & $\mathrm{C}(\%)$ & $\mathrm{D}(\%)$ & VCR & VCRS \\
\hline 1997 & 0,07 & 50,18 & 46,6 & 0,96 & 0,12 & 47,67 & 88,76 & 0,98 \\
1998 & 0,07 & 52,86 & 51,38 & 0,96 & 0,1 & 41,5 & 78,02 & 0,97 \\
1999 & 0,06 & 51,68 & 56,34 & 0,97 & 0,1 & 40,52 & 90,9 & 0,98 \\
2000 & 0,05 & 48,77 & 53,44 & 0,96 & 0,1 & 43,84 & 100,51 & 0,98 \\
2001 & 0,05 & 49,34 & 49,66 & 0,96 & 0,09 & 41,47 & 91,43 & 0,98 \\
2002 & 0,03 & 44,47 & 45,55 & 0,96 & 0,07 & 40,69 & 97,99 & 0,98 \\
2003 & 0,02 & 39,47 & 39,03 & 0,95 & 0,06 & 45,76 & 110,65 & 0,98 \\
2004 & 0,02 & 41,41 & 37,61 & 0,95 & 0,05 & 42,41 & 107,7 & 0,98 \\
2005 & 0,02 & 50,61 & 42,44 & 0,95 & 0,05 & 40,49 & 100,34 & 0,98 \\
2006 & 0,02 & 52,28 & 44,03 & 0,96 & 0,05 & 41,03 & 102,31 & 0,98 \\
2007 & 0,02 & 49,91 & 40,99 & 0,95 & 0,05 & 41,99 & 99,33 & 0,98 \\
2008 & 0,02 & 53,51 & 41,33 & 0,95 & 0,05 & 40,47 & 88,34 & 0,98 \\
2009 & 0,03 & 48,72 & 37,93 & 0,95 & 0,07 & 43,65 & 93,38 & 0,98 \\
2010 & 0,03 & 50,17 & 36,54 & 0,95 & 0,06 & 42,43 & 89,45 & 0,98 \\
2011 & 0,02 & 53,65 & 31,15 & 0,94 & 0,06 & 42,93 & 76,02 & 0,97 \\
\hline Média & 0,04 & 49,13 & 43,6 & 0,95 & 0,07 & 42,46 & 94,34 & 0,98 \\
\hline $1997 / 11$ & $-63,50 \%$ & $6,90 \%$ & $-33,20 \%$ & $-2,10 \%$ & $-53,30 \%$ & $-9,90 \%$ & $-14,30 \%$ & $-0,40 \%$ \\
$1997 / 03$ & $-66,60 \%$ & $-21,30 \%$ & $-16,20 \%$ & $-0,80 \%$ & $-50,30 \%$ & $-4,00 \%$ & $24,70 \%$ & $0,40 \%$ \\
$2004 / 11$ & $27,20 \%$ & $29,50 \%$ & $-17,20 \%$ & $-1,10 \%$ & $8,40 \%$ & $1,20 \%$ & $-29,40 \%$ & $-0,80 \%$ \\
\hline
\end{tabular}

Fonte: Os autores com base nos dados do Un Comtrade (2011).

Em que: $\mathrm{A}=$ Participação das exportações brasileiras de mate nas exportações totais brasileiras; $\mathrm{B}=$ Market share das exportações brasileiras de mate nas exportações mundiais de mate; $\mathrm{C}=$ Participação das exportações argentinas de mate nas exportações totais argentinas; $\mathrm{D}$ = Participação das exportações argentinas de mate nas exportações mundiais de mate; VCR = Vantagem Comparativa Revelada e VCRS = Vantagem Comparativa Revelada Simétrica.

No decorrer do período, as exportações brasileiras de mate cresceram $25,7 \%$, com um incremento na participação no mercado mundial do mate em $6,9 \%$, mas, mesmo assim, mostraram uma queda de $63,5 \%$ na participação das exportações totais realizadas pelo Brasil, passando de 0,07\% em 1997 para 0,02\% em 2011, por não terem conseguido acompanhar com a mesma intensidade a expansão das exportações gerais. Por outro lado, as exportações argentinas de mate exibiram maior representatividade nas exportações daquele país, constituindo, em $1997,0,12 \%$ das exportações realizadas $(47,5 \%$ a mais do que a representação do mate brasileiro) mas, assim como o Brasil, variaram negativamente, $-53,3 \%$, e passaram a representar em 2011 o equivalente a $0,06 \%$ das exportações totais argentinas.

É importante salientar que as exportações totais argentinas foram, no período analisado $62,7 \%$ menores do que as exportações totais brasileiras e cresceram menos. Enquanto as exportações totais argentinas cresceram no período $217,6 \%$, as exportações totais brasileiras cresceram 383,2\% (Figura 3). 

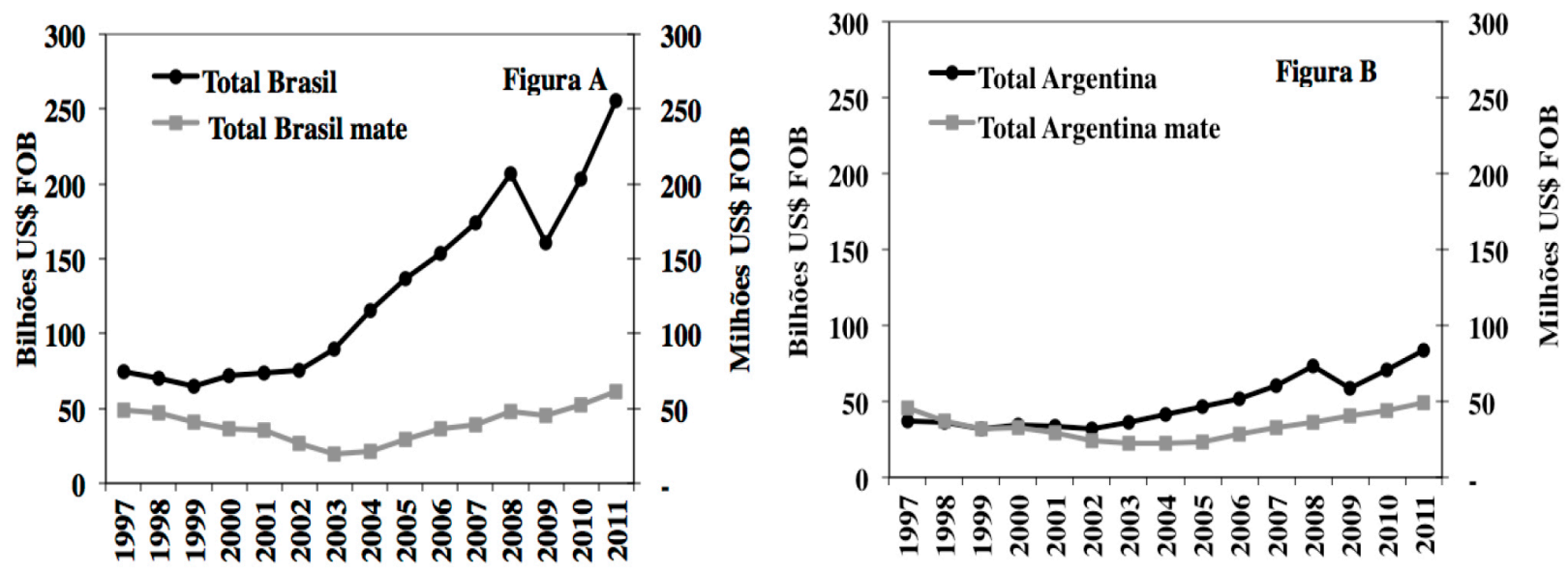

FIGURA 3: Exportações brasileiras totais e de mate, no período de 1997-2011; e Exportações argentinas totais e de mate, no período de 1997-2011.

FIGURE 3: Total and mate Brazilian exports, in the period 1997-2011; and Total and mate argentine exports, in the period 1997-2011.

Com relação ao IVCR, tanto o Brasil quanto a Argentina apresentaram um índice médio acima da unidade indicando vantagem comparativa extremamente forte para o mate (IVCR $>2,5$ ). No entanto, o valor do IVCR argentino $(\mu=94,3)$ foi mais expressivo que o IVCR brasileiro $(\mu=43,6)$, chegando a quase o dobro em comparação a esse. A partir disso, conclui-se que o setor de mate foi mais importante para a economia argentina do que para a brasileira, pois as exportações argentinas de mate contribuíram com uma maior parcela nas exportações totais argentinas, mesmo apresentando exportações totais do país menores em comparação com as exportações realizadas pelo Brasil no mesmo período (Figura 4).

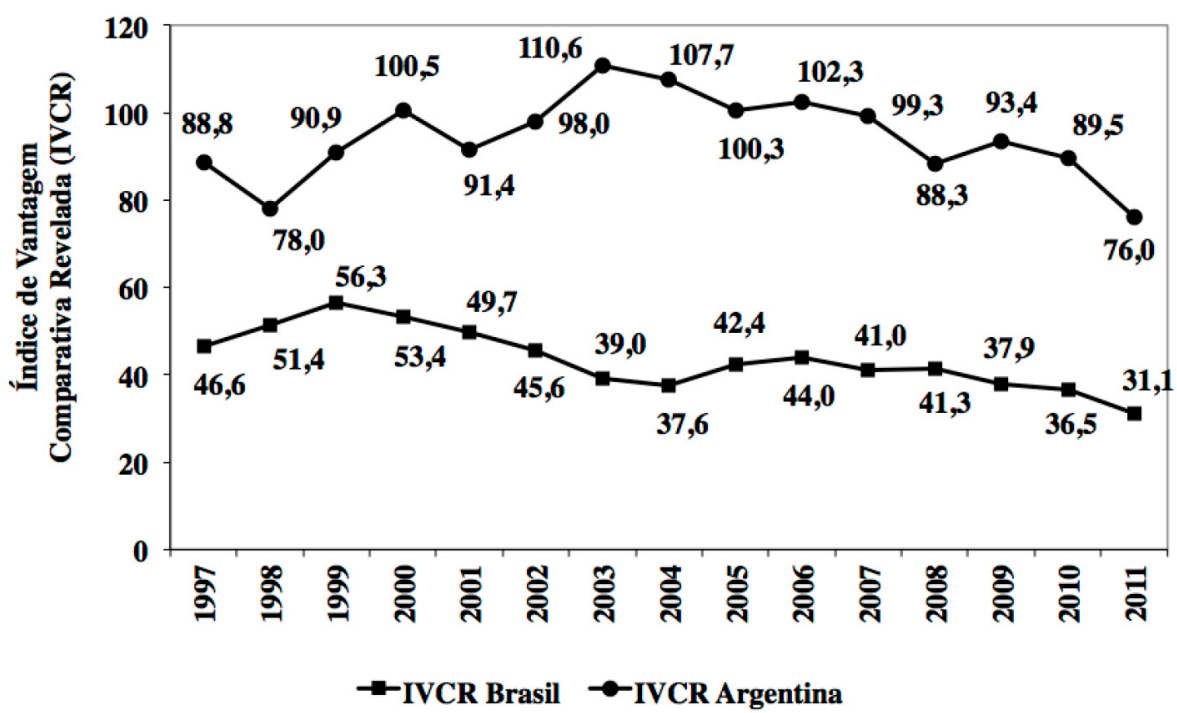

FIGURA 4: Índice de Vantagem Comparativa Revelada, no período de 1997-2011.

FIGURE 4: Revealed Comparative Advantage Index, in the period from 1997 to 2011.

No período total, os IVCRs argentino e brasileiro apresentaram queda de $-33,1 \%$ e $-14,3 \%$, mas ao analisar o comportamento da série respeitando os períodos identificados, esses valores sofrem alteração. Ao contrário do Brasil, em que o IVCR do mate apresentou uma queda de $-16,2 \%$, o IVCR do mate argentino cresceu 24,7\% de 1997 até 2003 e, partir de então, ambos declinaram alcançando no final do período (2011) os índices de 31,5 para o Brasil e 76,0 para a Argentina, apesar das exportações para ambos os países terem crescido no segundo subperíodo. 
O valor exportado do mate brasileiro superou em média $16,1 \%$ o do mate argentino, desta forma o valor das exportações argentinas e brasileiras formataram no total $42 \%$ e $49 \%$ das exportações mundiais de mate, respectivamente. Contudo, no quesito quantidade, as exportações argentinas de mate foram em média $20 \%$ maiores que as brasileiras, alcançando um preço médio $30 \%$ menor que o produto brasileiro. $\mathrm{O}$ que permite concluir que, como o cálculo do IVCR não contempla a variável quantidade exportada, o comportamento do IVCR do mate desses países não captou o aumento das exportações de mate ocorrida com os mesmos durante o segundo subperíodo. Nesse caso, a queda do IVCR no segundo subperíodo esteve relacionada às variações das exportações totais dos países envolvidos conforme visto anteriormente.

\section{Matriz de competitividade do mate brasileiro e argentino}

No período analisado (1997-2011), a taxa de crescimento do mercado mundial de mate atingiu $1,7 \%$ a.a. e o IVCRS brasileiro $(\mu=0,95)$ e argentino $(\mu=0,98)$ ficaram muito próximos da unidade, por isso, tanto o mate brasileiro quanto o argentino ficaram posicionados no quadrante superior direito da matriz de competitividade (Figura 5), ou seja, no período total podem ser considerados como setores ótimos.

Essa posição indica que ambos os países apresentaram produtos de mate que possuem vantagem comparativa revelada $(+)$ dentro de mercados com demanda crescente $(+)$. Desta maneira, conclui-se que o setor de mate foi competitivo e dinâmico para a economia brasileira e argentina.

No entanto, ao se analisar o primeiro subperíodo (1997-2003), o mate brasileiro e argentino situouse no quadrante superior esquerdo, indicando que, apesar do setor do mate em nível mundial na ocasião estar em declínio, os países analisados apresentaram um IVCR (+) para o mate.

Ao contrário disso, no segundo subperíodo (2004-2011), o produto brasileiro e argentino por apresentarem um IVCR $(+)$ em setores de demanda crescente $(+)$, mantiveram-se no quadrante superior direito, mas com uma taxa de crescimento (11,8\% a.a.) maior que aquela observada no período total $(1,6 \%$ a.a.). 


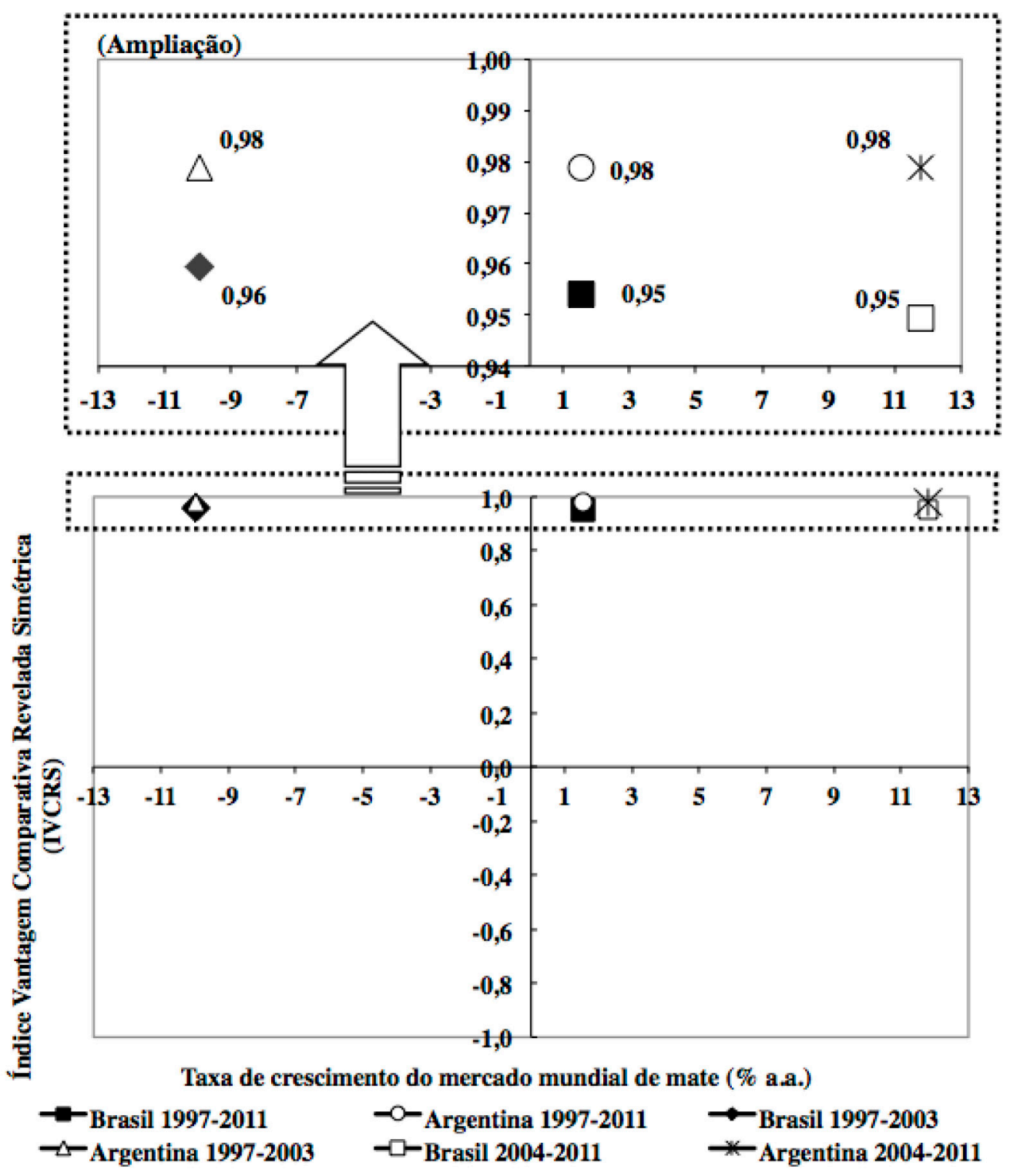

FIGURA 5: Matriz de competitividade do mate brasileiro e argentino, no período 1997-2011 e nos subperíodos 1997-2003 e 2004-2011.

FIGURE 5: Matrix of competitiveness of Brazilian and Argentine mate, in the period 1997-2011 and the sub periods 1997-2003 and 2004-2011.

\section{CONCLUSÕES}

No período analisado (1997-2011), as exportações mundiais de mate apresentaram uma taxa de crescimento positiva, indicando que a demanda foi dinâmica. Da mesma forma, tanto o mate brasileiro quanto o argentino apresentaram vantagens comparativas reveladas positivas e caracterizadas como extremamente forte, o que definiu que os setores nos dois países foram competitivos com relação às exportações de mate.

Apesar do Brasil ter apresentado uma maior participação no mercado mundial de mate, o IVCR do mate argentino se mostrou mais expressivo do que o produto brasileiro. Isso ocorreu devido às exportações argentinas de mate apresentarem maior representatividade nas exportações do país e essas serem menores e terem crescido menos que as exportações brasileiras.

No decorrer do período, os IVCRs brasileiro e argentino foram decrescentes, apesar das exportações de mate dos dois países terem crescido, pois ambos mostraram queda na participação com relação às 
exportações totais realizadas pelos seus respectivos países, por não conseguirem acompanhar com a mesma intensidade a expansão das mesmas.

No primeiro subperíodo (1997-2003), o setor do mate brasileiro e argentino apresentou-se em declínio com demanda não crescente, porém, no segundo subperíodo (2004-2011) esse setor, para os dois países, manteve uma taxa de crescimento maior que aquela observada no período total.

\section{REFERÊNCIAS}

ALMEIDA, A. N. et al. Análise do mercado dos principais produtos não-madeiráveis do estado do Paraná. Floresta, Curitiba, v. 39, n. 4, p. 753-763, out./dez. 2009a.

ALMEIDA, A. N. et al. Evolução da produção e preço dos principais produtos florestais não madeireiros extrativos do Brasil. Cerne, Lavras, v. 15, n. 3, p. 282-287, jul./set. 2009 b.

ALMEIDA, A. N.; SILVA, J. C. G.; ANGELO, H. Performance of softwood lumber export of Brasil e Canadá during the subprime crisis. Scientia Forestalis, Santa Maria, v. 40, n. 94, p. 267-277, 2012.

BAKHSHINEJAD, M.; ZADEH, A. H. Comparative advantage of selected agriculture products in Iran: a revealed comparative advantage assessment. World Applied Sciences Journal, Deira, v. 19, n. 10, p. 1449-1452, 2012.

BALASSA, B. 'Revealed' comparative advantage revisited: an analysis of relative export shares of the industrial countries, 1953-1971. The Manchester School of Economic and Social Studies, Manchester, v. 45, n. 4, 1977.

BALASSA, B. Trade liberalization and 'revealed' comparative advantage. The Manchester School of Economic and Social Studies, Oxford, v. 33, n. 2, p. 99-123, 1965.

BRAKMAN, S. et al. Cross-Border Merger and Acquisition activity and revealed comparative advantage in manufacturing industries. Journal of Economics and Management Strategy, Massachutts, v. 22, n. 1, p. 28-57, 2013.

BRASIL, A. A. As exportações brasileiras de painéis de madeira. Dissertação (Mestrado em Ciências Florestais) - Universidade Federal do Paraná, Setor de Ciências Agrárias, Área de economia e política florestal, Curitiba, 2002.

BRASIL. Ministério da Indústria, Comércio Exterior e Serviços. Aliceweb2: exportação 1997 - 2012 NCM 8 dígitos. Disponível em: <http://aliceweb2.mdic.gov.br/>. Acesso em: 02 jun. 2012.

CARVALHO, K. H. A. et al. Desempenho das exportações brasileiras de papel. Scientia Forestalis, Piracicaba, v. 38, n. 86, p. 263-271, jun. 2010.

CONFEDERAÇÃO NACIONAL DA INDÚSTRIA (Brasil). Pesquisa: os problemas da empresa exportadora brasileira: 2008. CNI: Brasília, 2008. 130 p.

COSTA, S. G. A erva mate. Curitiba: Secretaria do Estado do Planejamento e Coordenação Geral; Scientia et Labor, 1989.

COUTO, D. L. A.; FERREIRA, A. V. Vantagens comparativas reveladas das exportações do agronegócio mineiro para a União Européia: Um estudo de comércio exterior no período de 1996 a 2003. In: CONGRESSO BRASILEIRO DE ECONOMIA E SOCIOLOGIA RURAL, 48., 2010, Campo Grande. Anais... [s. 1.: s. n], 2010. CD-ROM.

COXHEAD, I. A new resource curse? Impacts of China's boom on comparative advantage and resourse dependence in Southeast Asia. World Development, Michigan, v. 35, n. 7, p. 1099-1119, 2007.

DANIEL, O. Erva-mate: sistema de produção e processamento industrial. Dourados: UFGD, 2009. 288 p. DE PAULA, M. L.; CHOCIAI, J. G. A erva-mate em cosméticos. In: MACCARI JUNIOR, A. (Coord.) Produtos alternativos e desenvolvimento da tecnologia industrial na cadeia produtiva da erva-mate. Curitiba: Câmara Setorial da Cadeia Produtiva da Erva-Mate do Paraná; Ministério da Ciência e Tecnologia; Conselho Nacional de Desenvolvimento Científico e Tecnológico, 2000. p. 136-160.

DIAS, L. C.; GIBBERTT, G. M.; SHIKIDA, P. F. A. Competitividade do açúcar brasileiro no mercado internacional. Revista de Economia e Agronegócio, Viçosa, MG, v. 4, n. 4, p. 457-484, 2008.

DIETER, M.; ENGLERT, H. Competitiveness in the global forest industry sector: an empirical study with special emphasis on Germany. European Journal of Forest Research, [s. 1.], v. 126, n. 3, p 401-412, 2007. FAJNZYBERG, F. Inserción internacional e inovación institucional. CEPAL, Santiago, n. 44, p. 137-166, 
1991.

FERNANDES, C. L. L.; VIEIRA FILHO, J. E. R. Especialização e competitividade de Minas Gerais no mercado internacional: um estudo de indicadores de comércio exterior no período de 1992 a 1999. 2000. Disponível em: <http://econpapers.hhs.se/bookchap/cdpdiaman/200013.htm> Acesso em: 18 set. 2013. GUJARATI, D. Econometria básica. 4. ed. Rio de Janeiro: Elsevier, 2006.

GUO, T.; WANG, Y.; NIE, Y. The study of the trade partner in China's agricultural products. Advances in Information Sciences and Service Science, Busan, v. 4, n. 19, p. 373-380, 2012.

HAN, X.; WEN, Y.; KANT, S. The global competitiveness of the Chinese wooden furniture industry. Forest Policy and Economics, Germany, v. 11, n. 8, p. 561-569, 2009.

HIDALGO, A. B. Especialização e competitividade do Nordeste no mercado internacional. Revista Econômica do Nordeste, Fortaleza, v. 29, nesp, p. 491-515, jul. 1998.

IBGE. Produção da extração vegetal e da silvicultura. Rio de Janeiro: IBGE, 2011. v. 26. 53 p.

ILHA, A. S.; CORONEL, D. A. Vantagens comparativas reveladas e orientação regional da soja brasileira frente à União Européia e ao foro de cooperação econômica da Ásia e no Pacífico (1992-2004). Revista de Economia e agronegócio, Viçosa, MG, v. 4, n. 1, 2006.

ILHA, A. S.; SOUZA, M. J. P. Índices de vantagem comparativas reveladas e orientação regional para alguns produtos do agronegócio brasileiro no período de 1992 a 2002. In: CONGRESSO BRASILEIRO DE ECONOMIA E SOCIOLOGIA RURAL, 43., 2005, Ribeirão Preto. Anais... Ribeirão Preto: SOBER, 2005. CD-ROM.

INSTITUTO NACIONAL DA PROPRIEDADE INDUSTRIAL (Brasil). Base de dados. [2013]. Disponível: <http://www.inpi.gov.br/>. Acesso em: 21 jun. 2013.

JACKMAN, M. et al. Evaluating tourism competitiveness of small island developing states: a revealed comparative advantage approach. Anatolia, London, v. 22, n. 3, p. 350-360, 2011.

KARAALP, H. S.; YILMAZ, N. D. Comparative advantage of textiles and clothing: evidence for Bangladesh, China, Germany and Turkey. Fibres and Textiles in Eastern Europe, Kaunas, v. 97, n. 1, p. 14-17, 2013. LAURSEN, K. Reveladed comparative advantage and the alternative as measures of internacional specialization. DRUID Working Paper, Copenhagen, n. 98-30, 1998.

LI, L.; DUNFORD, M.; YEUNG, G. International trade an industrial dynamics: geographical and structural dimensions of chinese and Sino-EU merchandise trade. Applied Geography, Georgia, n. 32, p.130-142, 2012.

LINHARES, T. História econômica do mate. Rio de Janeiro: José Olímpio, 1969.

MAHANZULE, R. Z. Dinâmica das exportações e avaliação da competitividade do setor de base florestal de Moçambique. 2013. 112 f. Dissertação (Mestrado em Engenharia Florestal) - Universidade Federal do Paraná, Setor de Ciências Agrárias, Centro de Ciências Florestais e da Madeira, Curitiba, 2013. MANDENG, O. International competitiveness and specializacion. CEPAL Review, Santiago, n. 45, p. 2540, 1991.

MAZUCHOWSKI, J. Z. Influência de níveis de sombreamento e nitrogênio na produção de massa foliar da erva-mate Ilex paraguariensis St. Hil. 2004. 113 f. Dissertação (Mestrado em Solos e Engenharia Agrícola) - Universidade Federal do Paraná, Setor de Ciências Agrárias, Curitiba, 2004.

MAZUCHOWSKI, J. Z.; RUCKER, N. G. A. Erva-Mate: prospecção tecnológica da cadeia produtiva. Documento Executivo. Curitiba: Secretaria de Estado da Agricultura e do Abastecimento do Paraná, Departamento de Economia Rural, 1997. 27 p.

MEDRADO, M. J. S.; VILCAHUAMAN, L. J. M. Importância socioeconômica e ambiental. Sistema de Produção. Brasília: EMBRAPA Florestas, 2010. Disponível em: <http://sistemasdeproducao.cnptia. embrapa.br/>. Acesso: 21 jun. 2013.

MOREIRA, S. L.; HERREROS, M. M.A. G. Uma análise da dinâmica competitiva internacional dos clusters exportadores no Brasil, 1990-2006. In: CONGRESSO BRASILEIRO DE ECONOMIA E SOCIOLOGIA RURAL, 2010, Campo Grande. Anais... Campo Grande: SOBER, 2010.

NAÇÕES UNIDAS. Comissão Econômica para a América Latina e Caribe. TradeCan 2002: un programa computacional sobre la competitividad internacional de los países. 2002. Disponível: $<$ http://www.eclac. org/ddpe/noticias/paginas/9/13779/guiatradecan_2002.pdf $>$. Acesso em: 20 jun. 2013.

OLIVEIRA, M. C. Estudo da erva-mate no Paraná: 1939-1967. Dissertação (Mestrado em História) -

Ci. Fl., v. 28, n. 4, out. - dez., 2018 
Setor de Ciências Humanas, Letras e Artes, Universidade Federal do Paraná, Curitiba, 1974.

OLIVEIRA, P. B. Competitividade e saldos comerciais da indústria agroalimentar no Brasil. 2005.

167 f. Dissertação (Mestrado em Economia) - Instituto de Economia, Universidade Federal de Uberlândia, Uberlândia, 2005.

ORGANIZAÇÃO DAS NAÇÕES UNIDAS PARAALIMENTAÇÃO EAGRICULTURA. Forest Products statistics. 2012. Disponível em: <http://www.fao.org/forestry/28808/en/>. Acesso em: 02 dez. 2012.

PAIS, P. S. M.; GOMES, M. F. M.; CORONEL, D. A. A análise da competitividade das exportações brasileiras de minério de ferro, de 2000 a 2008. Revista de Administração Mackenzie, São Paulo, v. 13, n. 4, p. 121-145, jul./ago. 2012.

PENA, H. W. A. Brasil e Coréia do Sul: uma análise comparativa da dinâmica das exportações no comércio internacional, 1985-2000. 2004. 197 f. Dissertação (Mestrado em Economia) - Universidade da Amazônia, Belém, 2004.

PETRAUSKI, S. M. F. C. Competitiveness of Brazil in the wood international market. Cerne, Lavras, v. 18, n. 1, p. 99-104, 2012.

RICARDO, D. On the principles of political economy and taxation. 1821. Disponível em: $<\mathrm{http}: / \mathrm{www}$. econlib.org/library/Ricardo/ricP1.html>. Acesso em: 20 ago. 2013.

SAINT-HILAIRE, A. Viagem à Comarca de Curitiba (1820). 4. ed. São Paulo: Companhia Editora Nacional, 1964.

SAMPIERI, R. H. Metodologia de pesquisa. 3. ed. São Paulo: McGraw Hill, 2006.

SERIN, V.; CIVAN, A. Revealed comparative advantage and competitiveness: a case study for Turkey towards the EU. Journal of Economic and Social Research, Istanbul, v. 10, n. 2, p. 25-41, 2008.

SILVA, P. P. M. G. Análise da competitividade revelada das flores de corte brasileiras no Mercosul e União Européia. 2012. 88 f. Dissertação (Mestrado em Administração e Desenvolvimento Rural) Departamento de Letras e Ciências Humanas, Universidade Federal Rural de Pernambuco, Guaranhuns, 2012.

UN COMTRADE. United Nations Commodity Trade Statistics Database: statistics division. 2012. Disponível em: <www.comtrade.un.org>. Acesso em: 14 jun. 2012.

U. S. DEPARTAMENT OF BUREAU OF LABOR STATISTICS. Consumer Price Index (CPI) Databases. 2012. Disponível em: < https://www.bls.gov/cpi/data.htm>. Acesso em: 14 jun. 2012.

VEGRO, C. L. R. Mercado de erva-mate no Brasil: História, situação e perspectivas. Informações Econômicas, São Paulo, v. 24, n. 12, dez. 1994.

WEI, Y.; FANG, R.; FENG, Y. The RCA index comparison of five countries: the analysis of potential impact upon Chinese tourism export and e-tourism services' trade. In: INTERNATIONAL CONFERENCE ON ARTIFICIAL INTELLIGENCE, MANAGEMENT SCIENCE AND ELECTRONIC COMMERCE, 2 ., 2011, Dengfeng. Anais... Dengfeng: IEEE, 2011, p. 5242-5245.

WORLD CUSTOMS ORGANIZATION. What is the Harmonized System (HS). 2013. Disponível em: $\quad<$ http://www.wcoomd.org/en/topics/nomenclature/overview/what-is-the-harmonized-system.aspx>. Acesso em: 01 jun. 2013.

XAVIER, C. L. Padrões de especialização e saldos comerciais no Brasil. 2001. Disponível em: <www. anpec.org.br/encontro2001/artigos/200103253.pdfP. Acesso em: 19 jun. 2013.

YUE, C.; HUA, P. Does comparative advantage explains export patterns in China? China Economic Review, Ohio, n. 13, p. 276-296, 2002.

ZHU, X.-Y.; ZHANG, Z.-G. Study on the international competitiveness of Chinese paper products from the point of view of forestry-paper integration. China Pulp and Paper, China, v. 29, n. 3, p. 71-75, 2010. 